\title{
The Effect of Rewards on Work Commitment of Nurses at Surgical and Medical Section (SMS) of National Hospital
}

\author{
C. M. Senanayake ${ }^{1 *}$ \\ ${ }^{I}$ Master of Human Resource Management, Bachelor of Science in Nursing, Special Grade Nursing Officer (Education), School of \\ Nursing, Kandana, Sri Lanka.
}

Received 10 January 2021; Revised 29 April 2021; Accepted 25 June 2021; Published 01 September 2021

\begin{abstract}
Background: Nurses are an essential component of health workforce. Therefore rewarding nurses is important to provide better service to the clients. The main purpose was to describe the effect of rewards on the work commitment of nurses at the SMS of National hospital. Objectives: to identify intrinsic and extrinsic rewards cause to the level of work commitment of nurses at SMS of National hospital, to determine the level of work commitment of nurses at SMS of National hospital, to measure the effect of socio-demographic factors on work commitment of nurses at SMS of National hospital and to describe the effect of rewards on work commitment of nurses at SMS of National hospital. Methodology: Descriptive, hospital-based, cross-sectional study design was used. Simple random sampling used to select 384 nurses. Data was collected using a self-administered questionnaire. Results: The mean value for composite intrinsic rewards was $3.34(\mathrm{SD}=0.57)$. There is a moderately positive Correlation $(\mathrm{r}=0.327, \mathrm{p}<0.000)$ between intrinsic rewards and the work commitment. The mean value for composite extrinsic rewards was $2.54(\mathrm{SD}=0.71)$ and it shows a very weak positive Correlation $(\mathrm{r}=0.167, \mathrm{p}<0.002)$ between extrinsic rewards and work commitment. As Socio-demographic factors, gender $\left(0.016^{* *}\right)$, age group $\left(0.117^{*}\right)$, position $\left(0.114^{*}\right)$, working experience at current work place $\left(0.154^{*}\right)$, and working section $\left(0.014^{* *}\right)$ have association with the overall work commitment of nurses. Level of work commitment of nurses was moderate $($ Mean $=3.13, \mathrm{SD}=0.35)$. Conclusion: Moderate correlation means, when increases intrinsic rewards, nurses' work commitment can be increased. Extrinsic rewards also cause to increase the commitment. Socio-demographic factors have an association with overall work commitment. These results help nurse managers to improve existing intrinsic rewards for nurses to enhance work commitment. Nurse Managers should suggest and plan a good reward system for nurses. Further research wants to conduct in government and private hospitals to find out ways to make nurses more committed. Moderate work commitment may be due to inadequate rewards or actually their dedication to the service without expecting rewards.
\end{abstract}

Keywords: Extrinsic Rewards; Intrinsic Rewards; National Hospital; Nurses; Work Commitment.

\section{Introduction}

Throughout past decades organizations have drastically changed. Not only organizations but also employees are changing. Different rewards are offering to employees for the recognition of their service, effort or achievements. Rewards play an important role in organizations influencing various work related behaviours and the motivation of employees [1]. In addition, most of the reward influence on work commitment of employees in the organizations. As health care delivery organizations, Hospitals are also changing. The employees working in hospitals play crucial roles to save the lives of people. Their workload also is increasing with a large number of clients, different new procedures and with new disease conditions, etc.

* Corresponding author: chandisenanayaka75@gmail.com

dol http://dx.doi.org/10.28991/SciMedJ-2021-0303-4

$>$ This is an open access article under the CC-BY license (https://creativecommons.org/licenses/by/4.0/).

(C) Authors retain all copyrights. 
Nurses are one of the most important human resources of hospitals and other health care organizations. Their influence on organizational performance is abundantly clear [2]. Nurses are the major care providers in every health care context. Their presence, perhaps, is a measure of the health care systems capacity to meet the needs of the world's people [3]

Rewards play a significant role in organizations influencing various work-related behaviors and the motivation of employees. Rewards usually important things to employees and provide numerous purposes in both public and private organizations. Bosco (2014) stated that praise and recognition are the most efficient intrinsic reward that enhances employee's performance [4]. Extrinsic rewards are tangible rewards and these rewards are concrete, external to the job or task performed by employee. Work commitment or organizational commitment is the bond employees experience with their organization. Employees who are committed to their organization generally feel a connection to the organization; they fit in and well understand the goals of the organization. In order to Allen and Meyer (1990), there are three types of organizational commitment. These are Affective commitment, Continuance commitment and Normative commitment [5].

Agus and Selvaraj (2020) conducted a cross-sectional study on the mediating role of employee commitment in the relationship between quality of work-life and the intentions to stay. Participants were nurses from four private hospitals in Malaysia. The study found that the strongest quality of work-life construct that contributed significantly to the intention to stay among respondents is work context, followed by work world, work design, and work life/home life. Further, the findings indicate that employee commitment partially mediates the relationship between quality of work life and the intention to stay. Researchers concluded that nurses are satisfied with their quality of work-life, the stronger will the nurses' commitment be in the organization and finally their intention to stay [6]. As per Dorgham (2012), it is significant in displaying how the organization has to work hard in order to keep its employees committed to the organization. Employees are the assets to the institute. The organizational culture is reflected in an organization's objectives. Objectives aim to develop employees by providing them a good working environment, and condition, assisting, and support them in having job satisfaction. Therefore these all will enhance commitment among the employees towards the organization. The study suggested that the management of the organization ought to provide necessary facilities and a favourable organizational climate. Further, it recommended taking actions that cater to the welfare of the workers to improve organizational commitment [7].

Seitovirta et al. (2017) found six meaningful types of rewards were identified by the registered nurses: Financial compensation and benefits, Work-Life balance, Work content, Professional Development, Recognition, and Supportive leadership. Rewards encouraged nurses to perform their work correctly. Rewards reinforced occupational satisfaction. This study highlighted that essential to pay attention to nurses' preferences for particular rewards. As per the study, when designing effective reward systems for nurses, it is not appropriate to provide only monetary rewards. Numerous types of nonmonetary rewards also are both meaningful and necessary [8]. Employees perceive incentives, rewards, and career progression as positive feedback for their work and contribution to the organization. These things make them more likely to involve in further innovation ideas. Mushtaq et al. (2020) concluded that nurse Leaders should be transparent, empowering, and helpful and allow decision-making freedom [9].

A study investigated by Kokubun (2018), on the relationship between rewards and organizational commitment of 12,076 employees at 32 Japanese manufacturing companies in Malaysia. The analysis revealed that all intrinsic, social, and extrinsic rewards are important for organizational commitment. According to findings, it was suggested that the antecedents of organizational commitment in Malaysia are different from those in the West or other lower- income Asian countries. The comparison between University graduates and others exhibited those extrinsic and intrinsic rewards had a stronger influence on organizational commitment in university graduates than in others. But social rewards had a weaker influence on organizational commitment. Satisfaction with personnel evaluation and autonomy were more strongly correlated with organizational commitment in university graduates while co-worker support and role clarity were more significantly correlated with organizational commitment in others. Other rewards, such as satisfaction with other treatments, supervisor support, and training, were equally correlated with organizational commitment in both university graduates and others [10].

Mabaso and Dlamini (2018) conducted quantitative research on impact of total rewards and their effects on the organizational commitment in higher education institutions. The sample size was 279 academic staff. The main findings showed a positive and significant correlation between elements of total rewards (performance management, recognition, talent development, and career opportunities, compensation, benefits, work-life balance and organizational commitment). A variance of $52.3 \%$ of total rewards explained organizational commitment. Performance management, compensation, benefits, recognition, talent development and career opportunities significantly predicted organizational commitment [11].

Nurses are the major human resource of the workforce of government hospitals of Sri Lanka. A Registered Nurse $(\mathrm{RN})$ is a nurse who has graduated from a nursing school and been registered and licensed from Nursing Council for practicing nursing. Their commitment is necessary for the promotion of health, prevention of illness, and the caring of 
ill, disable and dying persons. In Sri Lanka, nurses register and licensed from Sri Lanka Nursing Council. In Sri Lanka there are few types of government hospitals according to the bed strength and the facilities they provide to the clients. Among them the National Hospital of Sri Lanka (NHSL) is the main hospital. NHSL sometimes called General Hospital. It is the major government hospital in Colombo, Sri Lanka. This organization was established in 1864 at Hospital Street of Pettah as a General Hospital. NHSL is a leading hospital in Sri Lanka and is controlled by the central government. As well, it is the largest teaching hospital and the final referral center in the country. It is the training center for undergraduate and postgraduate trainees. Faculty of Medicine, University of Colombo, Nurses Training School, Post Basic Nursing School, and Schools of Radiography, Pharmacy, Cardiograph, Physiotherapy, and Occupational Therapy are also affiliated to the NHSL. The current bed strength is 3294 and has 84 wards (Male and Female Surgical, Medical and Special wards). There are eleven Teaching Hospitals, three Provincial General Hospitals, twenty District General Hospitals, Base Hospital types A and B, Divisional Hospital types A, B, and C, and Primary Medical Care Units. A large number of nursing workforce is delivering comprehensive care for clients in these hospitals. According to the current statistics, there is a nursing shortage while nearly 36000 nurses are employing in the public sector. This has a great deal of unwanted impact on the efficiency and effectiveness of the health care delivery system.

Although Sri Lankan Nurses represent the largest human resource element in the healthcare delivery system, it is difficult to find adequate literature related to nurses' rewards and work commitment. Sri Lankan nurses have to complete lots of tasks, duties and responsibilities with the heavy workload, long working hours and increasing night shifts in the work schedules. From the view of nursing expertise, nurses' turnover also increases and therefore retaining nurses is very important. Heavy nursing workload increases burnout and job dissatisfaction and leads to high nurse turnover [12]. Therefore both intrinsic and extrinsic rewards are more important for nurses. The theoretical gap also defined the problem of this study. Hence this study was significant. Therefore, the researcher decided to conduct the study under the purpose of describing the effect of rewards on the work commitment of nurses at SMS of NHSL. This article contains research problem, justification, research objectives, hypothesis, conceptual framework, methodology, data analysis, discussion of the results, and conclusion.

\subsection{Research Problem}

The existing theoretical research gap will be adopted to define the problem of this study specifically to the nurses working at SMS of NHSL. Most of the Ward Managers in SMS complain that nurses do not commit to their duties and responsibilities. Therefore, they face more difficulties to manage wards. At the same time, they complain that nurses complete mostly their personal achievements than job duties, tasks and responsibilities. From the nurses' point of view, they say that Nurse Managers do not consider rewards such as welfare facilities, work schedule, benefits, and leave for education, etc. and they expect only duties. As well new trend is increasing absenteeism, turnover the job without resigning and migrate without proper approval. As a result of those, the Ministry of Health recently makes actions to prohibit the immigration of nurses up to completing ten years of service in the public service in Sri Lanka.

\subsection{Justification}

Many studies undertaken in rewards and work commitment have identified that rewards effects on work commitment of nurses. Further, study evidence suggests that administrators, as well as nurse managers, should consider establishing good reward systems for nurses. Several other studies have documented that lack of rewards causes to turnover, job dissatisfaction and poor work commitment. Government allocates a huge amount of money for nursing training annually. Therefore Sri Lankan government nursing population is well trained, skilful, and knowledgeable and gives many advantages. Thus preventing turnover, improper migration and job satisfaction, etc. are significantly important to retain the trained workforce. Therefore, it is justifiable that a study ought to conduct on the effect of rewards on work commitment of nurses for Sri Lanka.

\subsection{Research Objectives}

The General objective of this study was to describe the effect of rewards on the work commitment of nurses at SMS of NHSL. Specific Objectives were to identify both intrinsic and extrinsic rewards cause to the level of work commitment of nurses at SMS of NHSL, to determine the level of work commitment of nurses at SMS of NHSL, to measure the effect of socio-demographic factors on work commitment of nurses at SMS of NHSL and to describe the effect of rewards on the work commitment of nurses at SMS of NHSL.

\subsection{Hypotheses}

$\mathrm{H}_{1}$ - It was assumed that intrinsic rewards provided to nurses can lead to enhance their work commitment at SMS of NHSL. $\mathrm{H}_{2}$ - It was assumed that extrinsic rewards provided to nurses can lead to enhance their work commitment at SMS of NHSL. $\mathrm{H}_{3}$ - It was assumed that demographical variables of nurses could moderate their work commitment at SMS of NHSL. 


\section{Research Methodology}

In this study the researcher used a quantitative, descriptive, hospital-based cross-sectional research design. According to this research background, the researcher used the Simple Random Sampling (SRS) approach to select the sample population from the target population. The total population of this research is all registered nurses currently employed at SMS of NHSL. From the total nursing population at SMS in NHSL, the researcher selected 384 nurses $(\mathrm{n}=384)$ from target population according to the Equation 1.

$n=\frac{Z^{2} p(1-p)}{d^{2}}$

The researcher used a pre-tested, content validated, self-administrated questionnaire to collect data from the participants. Ethical clearance obtained from the Ethics Review Committee of the NHSL, Colombo. SPSS version 22 was used to analyze the data.

Independent Factors

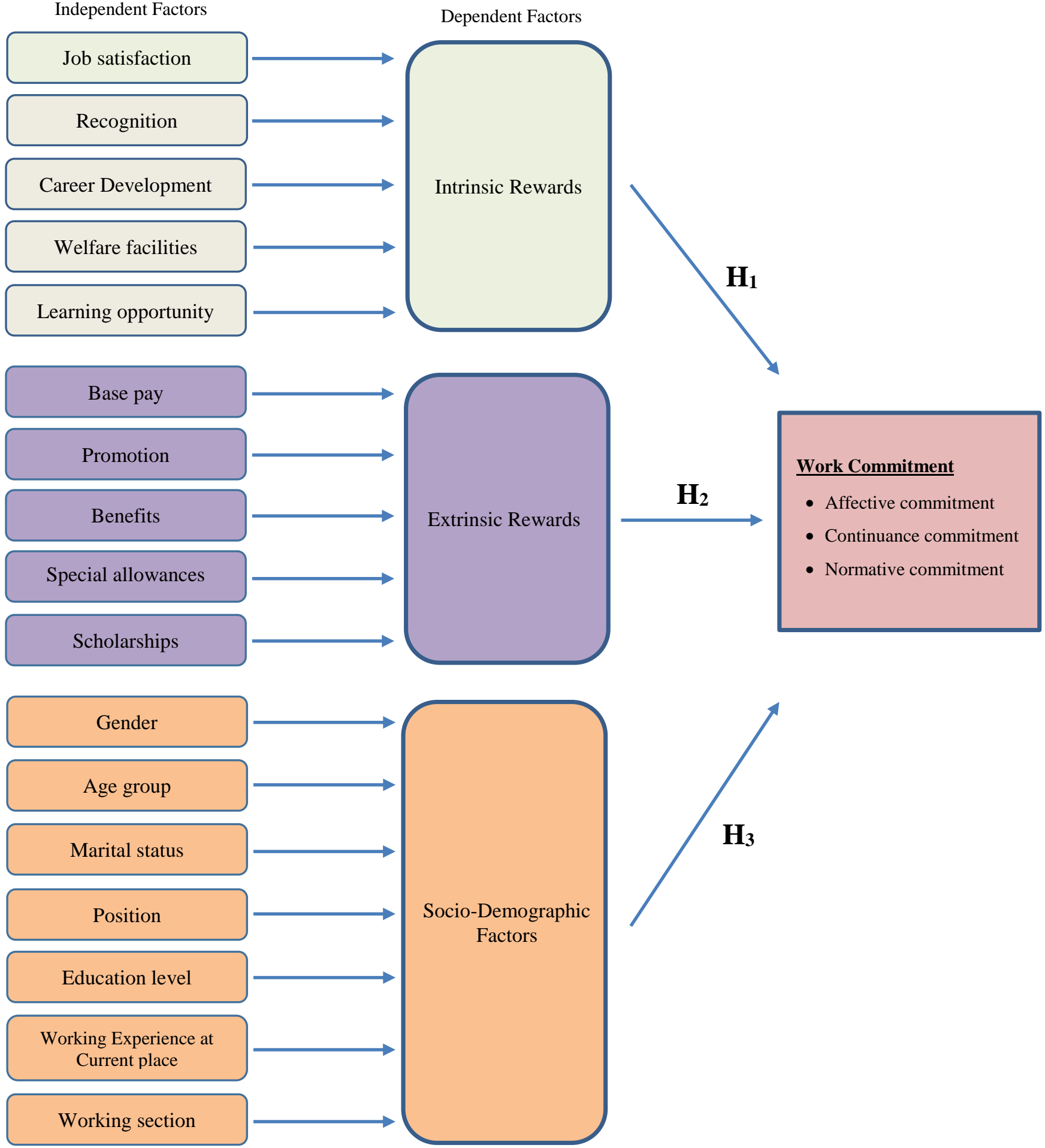

Figure 1. Conceptual framework 


\section{Data Analysis}

In terms of Gender $40(11.5 \%)$ were male participants and $307(88.5 \%)$ were female participants. Therefore the majority of the percentage is female and it is eight times of total male nurses in the whole sample. In terms of Age, these results highlight that majority $(54.2 \%)$ of respondents were 26 - 30 years of age group. Majority of the nurses are married $(56.2 \%)$ and the unmarried percentage is $42.4 \%$. The majority $(67.1 \%)$ of nurses includes to Grade III and is very limited percentage $(0.2 \%)$ belongs to the Supra Grade position. The Majority of the respondents were 307(88.8\%) were completed a Diploma holder which is a basic educational requirement for nurses. The highest percentage $(54.2 \%)$ of nurses has 1-10 years of experience and the minimum percentage of nurses $(0.3 \%)$ has 31 to 40 year experience. Composition of working section shows that $54.2 \%$ of nurses come from surgical wards and $45.8 \%$ come from medical wards. Then both working sections are approximately equal to the half of the total sample.

Table 1. Mean Score for Intrinsic Rewards and Extrinsic Rewards

\begin{tabular}{lccc}
\hline Intrinsic Rewards & Total, Mean (SD) & Surgical, mean (SD) & Medical, mean (SD) \\
\hline Job Satisfaction & $3.77(0.72)$ & $3.82(0.71)$ & $3.70(0.74)$ \\
Recognition & $3.35(0.80)$ & $3.57(0.80)$ & $3.60(0.80)$ \\
Career Development & $3.59(0.80)$ & $3.43(0.78)$ & $3.26(0.81)$ \\
Welfare Facilities & $2.82(0.91)$ & $2.78(0.89)$ & $2.87(0.94)$ \\
Learning Opportunity & $3.17(0.90)$ & $3.24(0.93)$ & $3.09(0.85)$ \\
Composite Intrinsic Rewards & $\mathbf{3 . 3 4}(\mathbf{0 . 5 7})$ & $\mathbf{3 . 3 7}(\mathbf{0 . 5 8})$ & $\mathbf{3 . 3 1}(\mathbf{0 . 5 5})$ \\
\hline Extrinsic Rewards & Total, Mean (SD) & Surgical, mean (SD) & Medical, mean (SD) \\
\hline Base Pay & $2.52(0.97)$ & $2.55(0.96)$ & $2.49(0.99)$ \\
Promotion & $2.61(0.92)$ & $2.70(0.90)$ & $2.50(0.94)$ \\
Benefits & $2.95(0.98)$ & $2.98(0.93)$ & $2.90(1.03)$ \\
Special Allowances & $2.32(0.91)$ & $2.28(0.91)$ & $2.36(0.90)$ \\
Scholarships & $2.31(1.01)$ & $2.36(1.04)$ & $2.26(0.96)$ \\
Composite Extrinsic Rewards & $2.54(0.75)$ & $2.57(0.74)$ & $\mathbf{2 . 5 0}(\mathbf{0 . 7 5})$ \\
\hline
\end{tabular}

Table 2. Mean Score Value for Work Commitment

\begin{tabular}{cccc}
\hline Work Commitment & Total, mean (SD) & Surgical, mean (SD) & Medical, mean (SD) \\
\hline Affective Commitment & $3.13(0.50)$ & $3.10(0.52)$ & $3.16(0.47)$ \\
Continuance Commitment & $3.17(0.52)$ & $3.15(0.53)$ & $3.20(0.50)$ \\
Normative Commitment & $3.10(0.51)$ & $3.02(0.49)$ & $3.19(0.51)$ \\
Overall Commitment & $\mathbf{3 . 1 3}(\mathbf{0 . 3 5})$ & $\mathbf{3 . 0 9}(\mathbf{0 . 3 6})$ & $\mathbf{3 . 1 8}(\mathbf{0 . 3 3})$ \\
\hline
\end{tabular}

Table 3. Association between Overall Work Commitment and Socio Demographic Factors

\begin{tabular}{llc}
\hline Variables & Statistical Test & $\begin{array}{c}\text { Asymptotic } \\
\text { Significance Value }\end{array}$ \\
\hline 1. Gender & t- test & $0.016^{* *}$ \\
2. Age group & One-way ANOVA & $0.117^{*}$ \\
3. Marital Status & One-way ANOVA & 0.220 \\
4. Position & One-way ANOVA & $0.114^{*}$ \\
5. Education Level & One-way ANOVA & 0.432 \\
6. Working Experience at current place & One-way ANOVA & $0.154^{*}$ \\
7. Working Section & t-test & $0.014^{* *}$ \\
\hline
\end{tabular}

* The variable is significant at $20 \%$

** The variable is significant at $5 \%$ level

The demographic factors such as gender, age, position, working experience at current place and working section have an association with overall work commitment at least $20 \%$ significant level. 
Table 4. Association between Overall Work Commitment and Composite Intrinsic Reward Scores and Extrinsic Reward Scores

\begin{tabular}{ccc}
\hline Variable & Pearson Correlation coefficient & P-value \\
\hline Intrinsic reward & 0.327 & $0.000^{* *}$ \\
Job Satisfaction & $\mathbf{0 . 3 0 8}$ & $\mathbf{0 . 0 0 0 * *}$ \\
Recognition & $\mathbf{0 . 2 8 7}$ & $\mathbf{0 . 0 0 0 * *}$ \\
Career Development & 0.219 & $0.000^{* *}$ \\
Welfare Facilities & 0.193 & $0.000^{* *}$ \\
Learning Opportunity & 0.142 & $0.008^{* *}$ \\
Extrinsic reward & $\mathbf{0 . 1 6 5}$ & $\mathbf{0 . 0 0 2} * *$ \\
Base pay & 0.038 & 0.481 \\
Promotion & 0.068 & 0.209 \\
Benefits & 0.077 & 0.152 \\
Special Allowances & 0.220 & $0.000^{* *}$ \\
Scholarships & 0.241 & $0.000^{* *}$ \\
\hline
\end{tabular}

\footnotetext{
* The variable is significant at $20 \%$

** The variable is significant at $5 \%$ level
}

Table 4 illustrated the positive association between overall work commitment and composite intrinsic rewards scores. Pearson correlation coefficient of overall intrinsic rewards is $0.327(\mathrm{r}=0.327, \mathrm{p}<0.000)$ and it shows there is a moderate positive association between overall work commitment and intrinsic reward scores.

The association between overall work commitment and composite extrinsic rewards scores shows a very weak positive association. Pearson correlation coefficient of overall extrinsic rewards is $0.165(\mathrm{r}=0.165, \mathrm{p}<0.002)$ and it means a weak positive correlation between extrinsic rewards and work commitment of the nurses at SMS of NHSL.

\section{Normal P-P Plot of Regression Standardized Residual}

\section{Dependent Variable: overall_commitment}

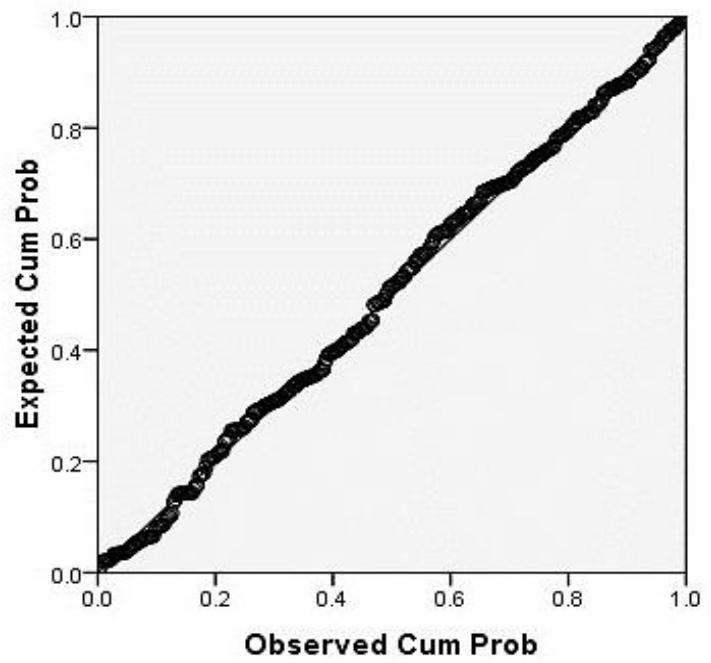

Figure 2. Normality of standardized residuals

The assumption of normality of error term is checked by visual inspection of normal probability plot as shown in Figure 2 all variables in normal probability plot fall along a diagonal line. This suggests that the regression variable meet the assumption of normality.

\section{Discussion}

Most of the individual $\mathrm{p}$-values of items also were $(\mathrm{p}<0.000)$. As it is lower than $\mathrm{p}<0.05$, it is considered to be statistically highly significant. The overall correlation coefficient of intrinsic rewards shows that there is a moderate positive correlation between intrinsic rewards and work commitment. The first objective of the study was to identify both intrinsic and extrinsic rewards caused by the level of work commitment of nurses at SMS of NHSL. Hence the study found that there is a relationship between intrinsic rewards and the level of work commitment of nurses at SMS of NHSL. 
Table 1 shows the Mean score value for each Intrinsic and Extrinsic Rewards with their Standard Deviation (SD). The overall mean value of Intrinsic Rewards is 3.34 ( $\mathrm{SD}=0.57)$. It is a little bit more than average value because the range of mean score value should be from 1 to 5 . When considering the mean score for the surgical section, it is 3.37 $(\mathrm{SD}=0.58)$ and it is more than the average value of mean score. Mean score for medical section is $3.31(\mathrm{SD}=0.55)$. These values are also little bit more than average value. Therefore, the above results indicate that generally work commitment of nurses is positively impacted by intrinsic rewards and supported the first hypotheses $\left(\mathrm{H}_{1}\right)$. The immaterial methods of rewarding discussed in the studies included verbal feedback, written or verbal recognition, demonstrations of appreciation and respect, the provision of training to facilitate employee development, and the maintenance of the hospital's good reputation [2]. However, overall extrinsic rewards show that there is a very weak positive significant correlation between extrinsic rewards and work commitment. Although the other three variables indicate large $\mathrm{p}$-values, the overall $\mathrm{p}$-value of extrinsic rewards $(\mathrm{p}<0.002)$ is below 0.05 . Therefore, overall extrinsic rewards are statistically highly significant and supported the second hypothesis $\left(\mathrm{H}_{2}\right)$. The first objective of the study was, to identify both intrinsic and extrinsic rewards caused by the level of work commitment of nurses at SMS of NHSL. As a result of the study mentioned, only two extrinsic rewards cause to the level of work commitment and three rewards showed a very weak correlation with the work commitment of nurses at SMS of NHSL.

Composite extrinsic variables show a 2.54 overall mean score and $(\mathrm{SD}=0.75)$ approximately equivalent for all variables. It is just past the average value. Only the Benefits reward has a little bit more mean value $($ mean $=2.95$, SD $=0.98$ ) than other mean values. Both surgical and medical section nurses have slightly increased overall mean values but just passed the average mean score. The mean value of the overall work commitment of nurses is 3.13 ( SD $=0.35$ ) as shown in Table 2. It is not much on the satisfaction side. Nurses from the surgical section showed a mean value of work commitment of $3.09(\mathrm{SD}=0.36)$ and it is also near to the total mean. Further, nurses from medical section indicates high mean value (mean $=3.16, \mathrm{SD}=0.47$ ) compared to surgical section [13]. Malhotra et al. (2007) highlighted the importance of both extrinsic and intrinsic rewards to develop affective, normative and continuance commitment in call center employees [14].

The total mean of Affective Commitment is $3.13(\mathrm{SD}=0.50)$ and it is similar to the overall mean of work commitment. Surgical section nurses indicate the 3.10 mean $(\mathrm{SD}=0.52)$. Medical section nurses show 3.16 of mean $(\mathrm{SD}=0.47)$. Between nurses at SMS show a very small difference. It implies that nurses in the study like to spend the rest of their career with this hospital, have a feeling of hospital problems as their own, sense of belonging, emotionally attached, and have felt as part of the family. Although that overall commitment is not much on the satisfaction side, it indicates that the nurses at SMS of NHSL are committed to the service. If the employee has a strong affective commitment, he or she will stay in the organization because he or she wants to. Personal characteristics and work experiences are the factors of affective commitment. Also, Lee (2010), Lee \& Cha (2015) supported those findings and examined that employee commitment involves an employee's dedication and the willingness to exert effort on behalf of an organization. Employee commitment is an emotional state. It demonstrates employees' relationships with an organization and the choice to stay in the organization $[15,16]$.

As a cost-induced commitment, the total mean of Continuance Commitment shows 3.17 ( $\mathrm{SD}=0.52$ ). Means of both surgical and medical sections approximately are similar to the means of the total mean. So the nurses at SMS of NHSL show a satisfactory level of Continuance Commitment. Meyer et al. (1993) and Meyer and Allen (1991) also supported with these findings, as Continuance Commitment entails employees being given an opportunity to leave the organization if they are rewarded with things like pay increase, status, freedom, and an increase in opportunity ${ }^{[15]}$. In order to that, employees with Continuance commitment stay not because they wants to but because forced to owing to what happens if they leave $[17,18]$. Al-Haroon and Al-Qahtani (2020) also supported with the findings of most nurses showed a moderate level of job commitment. Greater organizational commitment was positively related to sociodemographic variables and the only positive predictor of overall organizational commitment was age [19].

Responses based on how respondents understood Normative Commitment. Overall mean score of Normative Commitment is $3.10(\mathrm{SD}=0.51)$ and it is the least mean of three types of commitment. The mean of surgical and medical units are $($ mean $=3.09, \mathrm{SD}=0.36)$ and (mean $=3.18, \mathrm{SD}=0.33$ ) respectively. This implies that nurses in the sample are most likely to be motivated due to their obligation and loyalty to the NHSL. Accordingly, the nurses at SMS of NHSL show a satisfactory level of Normative Commitment. Normative commitment refers to employees' feelings of obligation to their superiors, peers, subordinates, and other third parties to remain within the organization [20-23]. Therefore, in order to effectively motivate nurses to improve work commitment, intrinsic and extrinsic rewards should be made regularly so that the rigor to work hard is equally facilitated. Samad (2007) highlighted that committed and satisfied employees are usually high performers and contribute towards organizational productivity [24].

According to Table 3, although Marital Status and Education Level have not associated with the overall work commitment, demographic factors such as gender, age, position, working experience at the current place and working section have an association with overall work commitment of nurses at least $20 \%$ significant level. It supported the 
third hypothesis $\left(\mathrm{H}_{3}\right)$. As per the study, though Marital Status has not associated with overall work commitment, the findings of Ouyang et al. (2015) said that nurse job satisfaction varied with respect to marital status [25].

Table 4 illustrated the positive association between overall work commitment and composite intrinsic and extrinsic rewards scores. The Pearson correlation coefficient of overall intrinsic rewards is 0.327 and it means that moderately positive correlation between intrinsic rewards and work commitment. Therefore, the nurses at SMS of NHSL are motivated to commit with overall intrinsic rewards. Overall $\mathrm{p}$-value of intrinsic rewards is $(\mathrm{p}<0.000)$. As it is lower than $\mathrm{p}<0.05$, it is considered to be statistically highly significant. Finally, all the intrinsic variables indicate strong evidence to support the hypothesis $\left(\mathrm{H}_{1}\right)$ which there is a relationship between intrinsic rewards provided to nurses and their work commitment at SMS of NHSL.

The association between overall work commitment and composite extrinsic rewards scores shows a weak positive association. The Pearson correlation coefficient of overall extrinsic rewards is 0.165 . It means that there is a very weak positive correlation between extrinsic rewards and work commitment of the nurses at SMS of NHSL. Overall p-value of extrinsic rewards is $(\mathrm{p}<0.002)$. As it is lower than $\mathrm{p}<0.05$, it can be considered as statistically highly significant. This small $\mathrm{p}$-value $(\mathrm{p}<0.002)$ indicates strong evidence to support the hypothesis. Special Allowances and Scholarships show strong evidence to support the hypothesis $(\mathrm{P}<0.000)$. Base pay $(\mathrm{P}>0.481)$, Promotion $(\mathrm{P}>0.209)$, and Benefits $(\mathrm{P}>0.152)$ have large p-values. Therefore those variables indicate the weak evidence to support the hypothesis. However, overall it shows a positive association between overall work commitment. Finally, overall there is a positive significant correlation between rewards and work commitment of nurses at SMS of NHSL.

\section{Conclusion}

The main purpose of the study was to describe the effect of rewards on the work commitment of nurses at SMS of NHSL. The results showed that there is a relationship between both intrinsic and extrinsic rewards and the work commitment of nurses at SMS of NHSL. Nurses more consider intrinsic rewards than extrinsic rewards. The overall intrinsic rewards show a moderately positive relationship. In addition, extrinsic rewards show a very weak relationship with a work commitment. But overall both rewards have a relationship with the work commitment of nurses and first and second hypotheses were supported. The demographic factors such as gender, age, position, working experience at the current place, and working section have an association with an overall work commitment. Marital Status and Education Level have not association with overall work commitment. Socio-demographic factors also effect on work commitment of nurses at SMS of NHSL and the third hypothesis was supported. There can be seen a moderately positive correlation between intrinsic rewards and work commitment. Therefore the nurses at SMS of NHSL are motivated to commit with overall intrinsic rewards.

Based on findings, nurse managers have an obligation to use good reward practices to greater the commitment of nurses. Therefore, nurse managers in SMS must consider new reward strategies to build a happier, committed, and productive nursing workforce. Nurse Managers need to acknowledge nurses' performance and create a good working culture in the work setting, motivate nurses by providing career growth prospects and other rewards. Since, the study has found that nurses consider both rewards, managers should investigate and find for most important rewards influencing on work commitment of nurses. As the NHSL is a specific study setting, it is better to carry out this study in other hospitals. The findings of this study are beneficial for both service and private sector hospitals. Therefore, another study must to be conducted to find out hidden factors.

\section{Declarations}

\subsection{Funding}

The author received no financial support for the research, authorship, and/or publication of this article.

\subsection{Acknowledgements}

The researcher would like to express heartfelt appreciation for NHSL and all nursing officers who participated in the study for giving their full cooperation.

\subsection{Ethical Approval}

All subjects gave their informed consent for inclusion before they participated in the study. The study was conducted in accordance with the approval of the Ethical Review Committee of the National Hospital of Sri Lanka. (ETH/COM/2018/06).

\subsection{Data Availability Statement}

The data presented in this study are available on request from the corresponding author. 


\subsection{Conflict of Interest}

The author declare that She/he has no known competing financial interests or personal relationships that could have appeared to influence the work reported in this paper.

\section{References}

[1] Opatha, H. H. (2016). Human Resource Management. (7th Edi.). Sri Lanka: Sharp Graphic House. doi:10.31357/bkc.fmsc.00001.

[2] De Gieter, S., De Cooman, R., Pepermans, R., Caers, R., Du Bois, C., \& Jegers, M. (2006). Identifying nurses' rewards: a qualitative categorization study in Belgium. Human Resources for health, 4(1), 1-8. doi:10.1186/1478-4491-4-15.

[3] Johnstone, M.-J. (2007). Nurse Recruitment and retention: Imperatives of imagining the future and taking a proactive stance. Contemporary Nurse, 24(2), iii-vi. doi:10.5172/conu.2007.24.2.iii.

[4] Bosco, B. M. (2014). Reward management practices and employee performance at Nakumatt holdings Ltd (Master thesis, University of Nairobi).

[5] Allen, N. J., \& Meyer, J. P. (1990). The measurement and antecedents of affective, continuance and normative commitment to the organization. Journal of Occupational Psychology, 63(1), 1-18. doi:10.1111/j.2044-8325.1990.tb00506.x.

[6] Agus, A., \& Selvaraj, R. (2020). The mediating role of employee commitment in the relationship between quality of work life and the intention to stay. Employee Relations: The International Journal, 42(6), 1231-1248. doi:10.1108/er-07-2019-0292.

[7] Dorgham, S. R. (2012). Relationship between Organization Work Climate \& Staff Nurses Organizational Commitment. Nature and Science, 10(5), 80-91.

[8] Seitovirta, J., Vehviläinen-Julkunen, K., Mitronen, L., De Gieter, S., \& Kvist, T. (2016). Attention to nurses' rewarding - an interview study of registered nurses working in primary and private healthcare in Finland. Journal of Clinical Nursing, 26(7-8), 1042-1052. doi:10.1111/jocn.13459.

[9] Mushtaq, M., Abid, G., Sarwar, K., \& Ahmed, S. (2017). Forging ahead: How to thrive at the modern workplace. Iranian Journal of Management Studies, 10(4), 783-818. doi:10.22059/ijms.2017.235409.672704.

[10] Kokubun, K. (2018). Education, organizational commitment, and rewards within Japanese manufacturing companies in China. Employee Relations, 40(3), 458-485. doi:10.1108/er-12-2016-0246.

[11] Mabaso, C. M., \& Dlamini, B. I. (2018). Total rewards and its effects on organisational commitment in higher education institutions. SA Journal of Human Resource Management, 16. doi:10.4102/sajhrm.v16i0.913.

[12] Van den Heede, K., Florquin, M., Bruyneel, L., Aiken, L., Diya, L., Lesaffre, E., \& Sermeus, W. (2013). Effective strategies for nurse retention in acute hospitals: A mixed method study. International Journal of Nursing Studies, 50(2), $185-194$. doi:10.1016/j.ijnurstu.2011.12.001.

[13] Ajmal, A., Bashir, M., Abrar, M., Mahroof Khan, M., \& Saqib, S. (2015). The Effects of Intrinsic and Extrinsic Rewards on Employee Attitudes; Mediating Role of Perceived Organizational Support. Journal of Service Science and Management, 08(04), 461-470. doi:10.4236/jssm.2015.84047.

[14] Malhotra, N., Budhwar, P., \& Prowse, P. (2007). Linking rewards to commitment: an empirical investigation of four UK call centres. The International Journal of Human Resource Management, 18(12), 2095-2128. doi:10.1080/09585190701695267.

[15] Lee, W. (2010). The Relationship between Job Characteristics and Job Satisfaction toward Affective Commitment; the Case of Engineers in Sepakat Setia Perunding SDN BHD. Unpublished MBA Project, University Sains Malaysia.

[16] Lee, E. J., \& Cha, P. (2015). Effects of Work Environment and Resilience on Job Satisfaction and Organisational commitment of Social Workers in Juvenile Reformatory Schools. Indian Journal of Science and Technology, 8(S1), 360. doi:10.17485/ijst/2015/v8is1/59331.

[17] Meyer, J. P., Allen, N. J., \& Smith, C. A. (1993). TCM Employee Commitment Survey. Academic Users Guide 2004. London, Ontario, Canada: The University of Western Ontario, Department of Psychology.

[18] Meyer, J. P., \& Allen, N. J. (1991). A three-component conceptualization of organizational commitment. Human Resource Management Review, 1(1), 61-89. doi:10.1016/1053-4822(91)90011-z.

[19] Al-Haroon, H. I., \& Al-Qahtani, M. F. (2020). Assessment of Organizational Commitment among Nurses in a Major Public Hospital in Saudi Arabia. Journal of Multidisciplinary Healthcare, Volume 13, 519-526. doi:10.2147/jmdh.s256856.

[20] Lephalala, R. P. (2006) Factors influencing nursing turnover in selected private hospitals in England, PhD dissertation, University of South Africa, Pretoria, South Africa.

[21] Erbasi, A., \& Arat, T. (2012). The Effect of Financial and Non-financial Incentives on Job Satisfaction: An Examination of Food Chain Premises in Turkey. International Business Research, 5(10). doi:10.5539/ibr.v5n10p136. 
[22] Hung, S. Y., Durcikova, A., Lai, H. M., \& Lin, W. M. (2011). The influence of intrinsic and extrinsic motivation on individuals' knowledge sharing behavior. International Journal of Human-Computer Studies, 69(6), 415-427. doi:10.1016/j.ijhcs.2011.02.004.

[23] Moloney, W., Fieldes, J., \& Jacobs, S. (2020). An Integrative Review of How Healthcare Organizations Can Support Hospital Nurses to Thrive at Work. International Journal of Environmental Research and Public Health, 17(23), 8757. doi:10.3390/ijerph17238757.

[24] Samad, S. (2007). Assessing the Effects of Job Satisfaction and Psychological Contract on Organizational Commitment among Employees in Malaysian SMEs. The 4th SMEs IN A Global Economy Conference.

[25] Ouyang, Y.-Q., Zhou, W.-B., \& Qu, H. (2015). The impact of psychological empowerment and organisational commitment on Chinese nurses' job satisfaction. Contemporary Nurse, 50(1), 80-91. doi:10.1080/10376178.2015.1010253. 


\section{Appendix I: Questionnaire}

Effect of Rewards on Work Commitment of Nurses at Surgical and Medical Sections in National Hospital of Sri Lanka.

Dear Participant,

The purpose of this study is to explore Effect of Rewards on Work Commitment of Nurses at Surgical and Medical Sections in National Hospital of Sri Lanka. Information collected in this study will be used to study purpose and will be kept completely confidential. No one at your work place will see this information. I am not asking you to provide your name on the questionnaire. I do not anticipate this questionnaire to cause any distress or risk. However if you feel uncomfortable please do not feel obligated to complete the questionnaire.

Thank you for your time and consideration.

\section{Questionnaire}

\section{Effect of Rewards on Work Commitment of Nurses at Surgical and Medical Sections in National Hospital of Sri Lanka}

Part A: Socio Demographic Data

Please indicate your answer by placing $(\sqrt{ })$ mark in front of the relevant box.

\begin{tabular}{|c|c|c|c|c|c|c|}
\hline 1 & Gender & Male & \multicolumn{2}{|c|}{ Female } \\
\hline 2 & Age (year) & $26-30$ & $31-35$ & \multicolumn{2}{|c|}{$36-40$} & Unmarried \\
\hline 3 & Marital state & Married & & \multicolumn{2}{|c|}{ Divorced } & Widow \\
\hline 4 & Position & Grade III & Grade II & Grade I & Supra Grade & Master \\
\hline 5 & Education & A/L & Diploma & Degree & Other (Specify) \\
\hline 6 & $\begin{array}{c}\text { Experience at current } \\
\text { work place }\end{array}$ & Less than 1 year & $1-10$ years & 11-20 years & $21-30$ years & $31-40$ years \\
\hline 7 & Working section & Surgical & & \multicolumn{2}{|c|}{ Medical } \\
\hline
\end{tabular}

\section{Part B: Rewards}

Please indicate your answer by placing $(\sqrt{ })$ mark in the relevant box according to the following rating scale.

Strongly Agree = 5; Agree = 4; Neutral = 3; Disagree $=2 ;$ Strongly Disagree $=1$

\section{Intrinsic Rewards}

\begin{tabular}{|c|c|c|c|c|c|c|}
\hline Se. No & Sentence & 5 & 4 & 3 & 2 & 1 \\
\hline \multicolumn{7}{|c|}{ I. Job Satisfaction } \\
\hline 8 & I feel valued for my contribution to the hospital. & & & & & \\
\hline 9 & I satisfy with our hospital culture. & & & & & \\
\hline \multicolumn{7}{|c|}{ II. Recognition } \\
\hline 10 & My supervisor appreciates my performance. & & & & & \\
\hline 11 & My supervisor allows me to take decision in critical situations. & & & & & \\
\hline \multicolumn{7}{|c|}{ III. Career Development } \\
\hline 12 & Hospital helps me to plan my career. & & & & & \\
\hline 13 & I have received special training opportunities. & & & & & \\
\hline \multicolumn{7}{|c|}{ IV. Welfare Facilities } \\
\hline 14 & Hospital provides good health facilities for nurses and their family members. & & & & & \\
\hline 15 & Nurses have adequate basic facilities during night shifts. & & & & & \\
\hline \multicolumn{7}{|c|}{ V. Learning Opportunity } \\
\hline 16 & It is easy to get duty leave for my higher education activities. & & & & & \\
\hline 17 & My supervisor studies encourages me for further & & & & & \\
\hline
\end{tabular}


Extrinsic Rewards

\begin{tabular}{|c|c|c|c|c|c|c|}
\hline Se. No & Sentence & 5 & 4 & 3 & 2 & 1 \\
\hline \multicolumn{7}{|c|}{ I. Base Pay } \\
\hline 18 & I satisfy with the basic salary. & & & & & \\
\hline 19 & I have earned my all increments up to date. & & & & & \\
\hline \multicolumn{7}{|c|}{ II. Promotion } \\
\hline 20 & My hospital always gives information about promotions. & & & & & \\
\hline 21 & I Satisfy with promotional opportunities in the organizations & & & & & \\
\hline \multicolumn{7}{|c|}{ III. Benefits } \\
\hline 22 & I have paid vacations. & & & & & \\
\hline 23 & I have flexible work schedules. & & & & & \\
\hline \multicolumn{7}{|c|}{ IV. Special Allowances } \\
\hline 24 & This hospital offers adequate allowances for nurses. & & & & & \\
\hline 25 & This hospital offers short term loan without delay. E.g. low interest loan. & & & & & \\
\hline \multicolumn{7}{|c|}{ V. Scholarships } \\
\hline 26 & The hospital offers me an opportunity for a Scholarship. & & & & & \\
\hline 27 & I am sure that I will select for the scholarship. & & & & & \\
\hline
\end{tabular}

\section{Part C: Work Commitment}

Please indicate your answer by putting $(\sqrt{ })$ mark on the relevant box.

\begin{tabular}{|c|c|c|c|c|c|c|}
\hline Se. No & Sentence & 5 & 4 & 3 & 2 & 1 \\
\hline \multicolumn{7}{|c|}{ I. Affective Commitment } \\
\hline 28 & I would be very happy to spend the rest of my career with this hospital. & & & & & \\
\hline 29 & I really feel as if this hospital's problems are my own. & & & & & \\
\hline 30 & I do not feel a strong sense of "belonging" to my hospital. (R) & & & & & \\
\hline 31 & I do not feel "emotionally attached" to this hospital. (R) & & & & & \\
\hline 32 & I do not feel like ,part of the family’ at Hospital. (R) & & & & & \\
\hline 33 & Hospital has a great deal of personal meaning for me. & & & & & \\
\hline \multicolumn{7}{|c|}{ II. Continuance Commitment } \\
\hline 34 & Right now, staying with my hospital is a matter of necessity as much as desire. & & & & & \\
\hline 35 & It would be very hard for me to leave my hospital right now, even if I wanted to. & & & & & \\
\hline 36 & Too much of my life would be disrupted if I decided I wanted to leave my hospital now. & & & & & \\
\hline 37 & I feel that I have too few options to consider leaving this hospital. & & & & & \\
\hline 38 & If I had not already put so much of myself into this organization, I might consider working elsewhere. & & & & & \\
\hline 39 & One of the few negative consequences of leaving this hospital would be the scarcity of available alternatives. & & & & & \\
\hline \multicolumn{6}{|c|}{ III. Normative Commitment } & \\
\hline 40 & I do not feel any obligation to remain with my current employer. (R) & & & & & \\
\hline 41 & Even if it were to my advantage, I do not feel it would be right to leave my hospital now. & & & & & \\
\hline 42 & I would feel guilty if I left my hospital now. & & & & & \\
\hline 43 & This hospital deserves my loyalty. & & & & & \\
\hline 44 & I would not leave my hospital right now because I have a sense of obligation to the people in it. & & & & & \\
\hline 45 & I owe a great deal to my hospital. & & & & & \\
\hline
\end{tabular}

End of the Questionnaire.

Thank you for your time and consideration. 